\title{
Cidades Virtuais: a inovação no processo de ensinoi aprendizagem universitário com a utilização do jogo SimCity
}

\author{
Virtual Cities: innovation in university teaching \\ and learning process using the SimCity game
}

\author{
Ciudades Virtuales: innovación en la enseñanza universitaria \\ y proceso de aprendizaje mediante el juego SimCity
}

Pablo Silva Lira ${ }^{1}$

\begin{abstract}
RESUMO
No século XXI, em plena revolução tecnológica e era da informação, o Professor é cotidianamente desafiado a se reinventar e buscar formas, processos, métodos, ferramentas e recursos didático-pedagógicos cativantes e inovadores. O modelo mental do estudante contemporâneo não se satisfaz com o tradicional ensinar por meio de lousa/quadro, giz/pincel e aula expositiva. Nesse contexto, o profissional-chave da educação deve lançar mão e se apropriar das novas tecnologias, na perspectiva da inovação, para tornar o processo de ensinoaprendizagem mais eficiente e eficaz. De maneira geral, este trabalho busca trazer à luz a experiência do projeto "Cidades Virtuais". O projeto "Cidades Virtuais" consiste na introdução planejada de uma dinâmica didático-pedagógica empreendida no curso de Arquitetura e Urbanismo da Universidade Vila Velha (UVV), que possibilita a utilização do famoso jogo SimCity para favorecer a conexão dos conhecimentos teóricoconceituais com as atividades práticas em ambiente virtual. Sendo implementado desde agosto de 2014, o referido projeto está proporcionando um maior envolvimento por parte dos alunos de Arquitetura e Urbanismo da UVV, bem como uma maior difusão, compartilhamento de ideias e inserção social de práticas de ensinoaprendizagem inovadoras, na comunidade científica, o que amplia as possibilidades de aperfeiçoamento e replicação.
\end{abstract}

PALAVRAS-CHAVE: Inovação. Processo de Ensinoaprendizagem. Tecnologias. SimCity.

\begin{abstract}
In the twenty-first century, in technological revolution and the information age, the teacher is daily challenged to reinvent herself and find ways, processes, methods, tools and engaging and innovative teaching-learning resources. The mental model of the contemporary student is not satisfied with the traditional teaching through blackboard, chalk and lecture. In this context, the teacher must take hold and take ownership of new technologies from the perspective of innovation, to make it more efficient and effective teaching-learning process. Overall, this work seeks to bring to light the experience of the project "Virtual Cities". The project "Virtual Cities" is the planned introduction of a didactic and pedagogical dynamics undertaken in the course of Architecture and Urbanism at the University Vila Velha (UVV), which enables the use of the famous SimCity game to favor the connection of theoretical and conceptual knowledge with activities practices in a virtual environment. Been implemented since August 2014, this project is providing a greater involvement by the students of Architecture and Urbanism of the UVV as well as greater dissemination, sharing of ideas and social integration of innovative teaching and learning practices in the scientific community, which expands possibilities for improvement and replication.
\end{abstract}

KEYWORDS: Innovation. Process of Teaching and Learning. Technologies. SimCity.

\footnotetext{
${ }^{1}$ Doutorando em Geografia - Universidade Federal do Espirito Santo (UFES) - Vitória, ES - Brasil. Mestre em Arquitetura e Urbanismo pela Universidade Federal do Espirito Santo (UFES) - Vitória, ES - Brasil. Professor da Universidade Vila Velha (UVV) - Vila Velha, ES - Brasil.

E-mail: pabloslira@gmail.com. ORCID: http://orcid.org/0000-0002-2643-5219.
}

Submetido em: 29/04/2016 - Aceito em: 15/06/2016

(C) ETD-Educação Temática Digital Campinas, SP v.19 n.2 $\quad$ p. 532-549 abr./jun. 2017 


\section{RESUMEN}

En el siglo XXI, en plena revolución tecnológica y la era de la información, el profesor tiene el desafío de reinventarse a sí mismos y encontrar formas, procesos, métodos, herramientas y recursos de enseñanzaaprendizaje innovadores. El modelo mental del estudiante contemporáneo no está satisfecho con la enseñanza tradicional a través de la pizarra, tiza y clase de exposición. En este contexto, el profesor debe utilizar las nuevas tecnologías, en perspectiva de la innovación, para que sea más eficiente y eficaz lo proceso de enseñanza-aprendizaje. En general, este trabajo pretende dar a conocer la experiencia del proyecto "Ciudades Virtuales". El proyecto "Ciudades Virtuales" es la introducción prevista de una dinámica didáctica y pedagógica realizada en el curso de Arquitectura y Urbanismo de la Universidad de Vila Velha (UVV), lo que permite el uso del famoso juego SimCity para favorecer la conexión con el conocimiento teórico y conceptual con actividades prácticas en el entorno virtual. Puesto en práctica desde agosto de 2014, este proyecto está permitiendo una mayor implicación de los estudiantes de Arquitectura y Urbanismo de la UVV, así como una mayor difusión, el intercambio de ideas y la integración social de las prácticas de enseñanza y aprendizaje innovadores, la comunidad científica, lo que amplía las posibilidades de reproducción y de mejora del proyecto "Ciudades Virtuales".

PALABRAS CLAVE: Innovación. Proceso de Enseñanza-aprendizaje. Tecnologías. SimCity.

\section{INTRODUÇÃO}

As estatísticas oficiais indicam que mais da metade da população mundial reside em áreas urbanas. A Organização das Nações Unidas (ONU) estima que em 2050, aproximadamente, $70 \%$ da população do globo residirá em cidades. Segundo dados de 2014 do Instituto Brasileiro de Geografia e Estatística (IBGE), países como Argentina (91,6\%), Bolívia (68,1\%), Brasil $(85,4 \%)$, Chile $(89,3 \%)$, Colômbia $(76,1 \%)$, Equador $(63,5 \%)$, Paraguai $(59,4 \%)$, Peru $(78,2 \%)$, Uruguai $(95,1 \%)$ e Venezuela $(88,9 \%)$, que evidenciaram intensos processos de industrialização ao longo do século XX, destacam na atualidade elevadas taxas de urbanização. No referido século, a cidade se consolidou como o lócus privilegiado de produção do capital, grandes investimentos, interesses financeiros e concentração populacional (LEFEBVRE, 1999).

Via de regra, a industrialização desses países promoveu o crescimento econômico desvinculado do desenvolvimento social. Como reflexo desse modelo que predominou na América do Sul, uma série de problemáticas, a saber, aprofundamento das desigualdades socioeconômicas, degradação ambiental, desordenamento territorial, (i)mobilidade urbana e aumento das violências, passaram a compor o cotidiano das principais cidades dessa região (SANTOS, 2005; RIBEIRO, 2013).

A teoria e pensamento sobre o fenômeno urbano constituem relevantes catalisadores na busca pela implementação de um modelo de desenvolvimento mais sustentável que permita mitigar e/ou solucionar as problemáticas aqui mencionadas (CAVALCANTI, 1995). A produção de conhecimento e formação universitária de estudantes 
de Arquitetura e Urbanismo, Geografia, Economia, Ciências Sociais, História e outros campos do saber, que refletem sobre as questões urbanas, devem propiciar um pensamento transformador para suplantar os principais gargalos enfrentados pelas cidades contemporâneas.

Para isso, o docente no século XXI deve buscar inovar nas práticas de ensinoaprendizagem visando estimular um maior aprofundamento sobre as nuanças do fenômeno urbano na coetaneidade (MASSEY, 2008) e despertar o interesse dos estudantes para transformar os ambientes urbanos de países da América Latina e outras partes do globo. Nesse sentido, o trabalho que aqui se insere busca descrever o projeto "Cidades Virtuais", que está sendo implementado no curso de graduação de Arquitetura e Urbanismo da Universidade Vila Velha (UVV), localizada no estado do Espírito Santo - Brasil.

\section{CONTEXTUALIZAÇÃO DO PROJETO}

O projeto "Cidades Virtuais" foi desenvolvido para ser aplicado, inicialmente, nas turmas do 5ำ período do curso de graduação de Arquitetura e Urbanismo da UVV, como escopo da disciplina de Fundamentos Sociais, Econômicos e Ambientais de Arquitetura e Urbanismo. Esta é uma disciplina que compõe a grade teórica do citado curso e possui um plano com uma carga relevante de leitura de referenciais do campo da Arquitetura e Urbanismo.

A partir de 2013, nos primeiros períodos ministrando a disciplina de Fundamentos, o docente percebeu que os discentes acabavam reclamando da "carga de leitura" prevista no plano e colocada em prática nas aulas expositivas ministradas em sala, atividades programadas de seminários e elaboração de textos para discussão.

Identificado este problema, o docente se motivou a empreender formas, processo, métodos, ferramentas e recursos didático-pedagógicos mais cativantes e inovadores. De acordo com o Manual de Osloii, a inovação é a implementação de um produto (bem ou serviço) ou processo novo ou significativamente melhorado (OCDE, 2005, § 146).

No século XXI, a inovação tecnológica no processo de ensinoaprendizagem implementado por meio da utilização de jogos eletrônicos vem sendo estudada e indicada, por vários pesquisadores (MENDES; GRANDO, 2008), como um caminho diferencial para o aprimoramento da relação docente-discente nos ambientes universitários, onde o intercâmbio de ideias científicas deve ser otimizado em prol da produção do conhecimento, no caso do referido projeto, no campo da Arquitetura e Urbanismo.

\section{(c) ETD-Educação Temática Digital Campinas, SP v.19 n.2 $\quad$ p. 532-549 abr./jun. 2017}


Partindo desta premissa, este projeto foi concebido no 10 semestre de 2014 por meio de um insight que surgiu durante um dos treinamentos do corpo docente da Universidade Vila Velha (UVV), no qual a Pró-reitoria Acadêmica instigou o desenvolvimento de práticas inovadoras de ensinoaprendizagem. Dessa ideia resultou o projeto "Cidades Virtuais", que aqui é apresentado. O mesmo foi implementado, em caráter experimental, no 2o semestre letivo de 2014 na disciplina de "Fundamentos sociais, econômicos e ambientais de arquitetura e urbanismo" com os alunos do 5o período da graduação de Arquitetura e Urbanismo da referida Instituição.

De maneira geral, o projeto consiste na introdução de uma dinâmica didáticopedagógica que possibilita a utilização do famoso jogo SimCity iii para favorecer a conexão dos conhecimentos teórico-conceituais da disciplina de Fundamentos com práticas em ambiente virtual. O jogo SimCity é um simulador computacional de gestão de cidades e possui amplo potencial de utilização no ensino de Arquitetura e Urbanismo, Geografia, Administração, Direito, Pedagogia, Economia, Sociologia, Biologia, Engenharia Ambiental, Estatística, Matemática e outros cursos. A disciplina de Fundamentos pertence ao quadro teórico da grade de Arquitetura e Urbanismo. A inserção da citada dinâmica, articulada no plano da disciplina, justifica-se por aprimorar o processo de ensinoaprendizagem e estimular o desenvolvimento de competências, habilidades e atitudes nos discentes de forma lúdica e inovadora.

No referido processo, a inovação tecnológica cumpre um papel essencial em prol do avanço e aprimoramento no ensino científico de Arquitetura e Urbanismo, ao ponto de possibilitar a construção de perspectivas alternativas para compreender e reinventar práticas relativas à teoria e pensamento sobre o fenômeno urbano.

\section{A UTILIZAÇÃO DE JOGOS NO ENSINOAPRENDIZAGEM}

Como visto, uma das justificativas do projeto, aqui descrito, é aperfeiçoar o processo de ensinoaprendizagem e estimular o desenvolvimento dos estudantes de forma lúdica e inovadora. A utilização do jogo SimCity, como ferramenta didático-pedagógica nas aulas da disciplina de Fundamentos do curso de Arquitetura e Urbanismo, caracteriza-se como o principal diferencial deste projeto.

Por ser, na maioria das vezes, encarada como uma dinâmica diferencial e inovadora, a utilização de jogos pedagógicos no processo de ensinoaprendizagem possui potencial de se propagar para o espaço extraclasse em discussões profícuas com colegas de curso, amigos e parentes, o que é muito importante para o desenvolvimento da capacidade de

(c) ETD-Educação Temática Digital Campinas, SP v.19 $\quad$ n.2 $\quad$ p. 532-549 abr./jun. 2017 
comunicação e argumentação do aluno. Além disso, o referido jogo possibilita atrelar o conhecimento teórico-conceitual da disciplina de "Fundamentos sociais, econômicos e ambientais" com práticas instigantes e cativantes que são desenvolvidas em cidades que são simuladas em ambiente virtual.

Moura (1992) entende jogo pedagógico como uma ferramenta que pode ser utilizada no processo de ensinoaprendizagem ampliando as perspectivas didáticas. Muitas podem ser as possibilidades, "quando se propõe o uso pedagógico dos jogos, como por exemplo, a construção e/ou a fixação de conceitos, a mobilização, a possibilidade de aprender a trabalhar em grupos, o desenvolvimento da criticidade e da cidadania" (GRANDO apud MENDES; GRANDO, 2008, p. 120). No ensinoaprendizagem de Arquitetura e Urbanismo não é diferente, Nascimento e Albuquerque (2015) indicam como os jogos pedagógicos podem potencializar as experiências em sala de aula, desde uma atividade sobre um edifício híbrido desenvolvido em uma disciplina de ateliê, até um projeto urbanístico pensado em uma atividade de planejamento urbano.

Para Mendes e Grando (2008) ao trabalhar com os jogos e simuladores computacionais, o professor propicia ao aluno a oportunidade de vivenciar o conhecimento e saber de uma maneira crítica, em um contexto tecnológico. Um aluno do centro de formação de condutores, um piloto de avião e um piloto de Formula 1 são submetidos a horas de simulação para, respectivamente, tirar carteira de motorista, tirar o brevê de piloto e melhorar seu desempenho em pistas de corrida. Nesses três exemplos, o simulador computacional é utilizado para testar e aprimorar as competências, habilidades e atitudes dos atores envolvidos. O propósito de utilizar o simulador de cidades SimCity na formação dos estudantes de Arquitetura e Urbanismo é bem semelhante.

A utilização do jogo SimCity apresenta interface que favorece o ensinoaprendizagem de alguns dos conhecimentos, competências, habilidades e atitudes explicitados nas Diretrizes Curriculares Nacionais (DCN) da graduação de Arquitetura e Urbanismo (Resolução CNE/CES no 02/2010), Diretrizes Gerais e Específicas do ENADE (Portarias Inep no 255 e 233/2014) e Diretrizes do Projeto Pedagógico da graduação de Arquitetura e Urbanismo da Universidade Vila Velha (UVV), a saber:

- O conhecimento dos aspectos antropológicos, sociológicos e econômicos relevantes e de todo o espectro de necessidades, aspirações e expectativas individuais e coletivas quanto ao ambiente construído (DCN);

- A compreensão das questões que informam as ações de preservação da paisagem e de avaliação dos impactos no meio ambiente, com vistas ao equilíbrio ecológico e ao

\section{(C) ETD-Educação Temática Digital Campinas, SP v.19 n.2 p.532-549 abr./jun. 2017}


desenvolvimento sustentável (DCN);

- Os conhecimentos de teoria e de história da arquitetura, do urbanismo e do paisagismo, considerando sua produção no contexto social, cultural, político e econômico e tendo como objetivo a reflexão crítica e a pesquisa (DCN);

- Extrair conclusões por indução e/ou dedução (ENADE);

- Estabelecer relações, comparações e contrastes em diferentes situações (ENADE);

- Fazer escolhas valorativas avaliando consequências (ENADE);

- Argumentar coerentemente (ENADE);

- Propor soluções para situações-problema (ENADE);

- As habilidades necessárias para conceber projetos de arquitetura, urbanismo e paisagismo em todas as suas escalas e para realizar construções; considerando os fatores de custo, de durabilidade, de manutenção e de especificações; considerando os regulamentos legais, as políticas públicas e habitacionais, de modo a satisfazer as exigências culturais, econômicas, estéticas, técnicas, ambientais, de segurança, de desempenho, ergonômicas e de acessibilidade e mobilidade dos usuários (ENADE);

- O domínio de conhecimento e técnicas necessárias para a gestão e coordenação da produção de obras civis e de urbanização (ENADE);

- A sensibilidade para conceber projetos de arquitetura, urbanismo e paisagismo relacionados à participação e a inclusão sociais e com vistas no desenvolvimento de uma sociedade sustentável (UVV); e

- O conhecimento da tecnologia como base para desenvolvimento de soluções criativas e inovadoras (UVV).

Nesse sentido, este projeto também possui como justificativa a promoção do desenvolvimento contínuo desses relevantes conhecimentos, competências, habilidades e atitudes intrínsecas à disciplina de fundamentos e que são potencializadas com a dinâmica didático-pedagógica aqui especificada.

\section{OPORTUNIDADES PERCEBIDAS}

É comum ouvir dos estudantes de Arquitetura e Urbanismo que alguns deles se identificam e optam por prestar o vestibular para o citado curso de graduação devido, dentre outros fatores, às experiências e à familiarização com o SimCity.

Este é um jogo computacional, gênero simulador, que esteve presente na adolescência e juventude de várias gerações. Sua primeira versão é de 1989 e desde este período o potencial educacional do jogo se destacava em meio à diversão e entretenimento. Anos depois, já na década de 90, uma versão do jogo foi lançada para o famoso videogame

\section{(C) ETD-Educação Temática Digital Campinas, SP $\quad$ v.19 n.2 $\quad$ p. 532-549 abr./jun. 2017}


Super Nintendo, o que contribuiu para sua popularização. A partir dos anos 2000, o SimCity ganhou maior realismo com os avanços tecnológicos alcançados pela microinformática, que passaram a permitir um processamento gráfico de melhor qualidade e de forma mais eficiente, introduzindo elementos em perspectiva 3D.

O jogo SimCity acompanhou a evolução tecnológica da virada do século XX para o século XXI e até hoje continua ganhando adeptos interessados em simular experiências de gerenciamento de cidades. Esta ferramenta tecnológica é compatível com os meios e estilos de comunicação das gerações contemporâneas. Seu valor educacional mostra-se mais presente do que nunca, pois o nível de realismo, propiciado pelos componentes eletrônicos de processamento gráfico de última geração, cativa a atenção dos jogadores ao mesmo tempo em que os desafia para refletir sobre questões urbanas típicas do século XXI.

Com base nestas oportunidades, o projeto que aqui é apresentado busca melhorar e otimizar o ensinoaprendizagem de Arquitetura e Urbanismo ao introduzir dinâmicas didático-pedagógicas no plano da disciplina de Fundamentos que viabilizam a utilização educacional do jogo SimCity.

O projeto "Cidades Virtuais" visa estimular os alunos a refletir de forma inovadora, em uma perspectiva heurística, para encontrar soluções, com base nas teorias trabalhadas nas aulas expositivas, para problemas complexos no campo da Arquitetura e Urbanismo. Dessa forma, os alunos simulam, com a orientação do Professor, possíveis alternativas para mitigar ou resolver questões sociais, econômicas e ambientais nas cidades virtuais. Neste laboratório, os alunos aprendem e exercitam competências e habilidades e são preparados para lidarem com situações que exigirão atitudes e conhecimentos aprimorados sobre a sustentabilidade do meio urbano. Nossos futuros arquitetos e urbanistas, com a referida dinâmica, também exercitam e desenvolvem suas capacidades técnicas, de liderança, de gestão e de trabalho em equipe, bem como princípios de ética e cidadania.

O escopo da disciplina de "Fundamentos sociais, econômicos e ambientais de Arquitetura e Urbanismo", na qual o projeto foi desenvolvido, é orientado pelos preceitos da ética, cidadania, diversidade e sustentabilidade. 0 jogo utilizado por este projeto na verdade se caracteriza como um catalisador destes preceitos, pois coloca os alunos em um ambiente virtual na posição de gestores e planejadores urbanos, cujas tomadas de decisão, impactam na vida da sociedade, nas finanças, na economia e nas condições ambientais do sítio urbano trabalhado. 
Nessa lógica, os desdobramentos deste projeto possuem grande probabilidade de resultarem em ações de inclusão social, uma vez que as competências e habilidades desenvolvidas em sala de aula durante a disciplina de Fundamentos apresentam potencialidade de serem aprimoradas ao longo do curso, sobretudo, no período de elaboração do Trabalho de Conclusão de Curso (TCC), quando os alunos passam a desenvolver atitudes que encontram maior respaldo na aplicabilidade de gerar retorno para a sociedade com base nos conhecimentos adquiridos ao longo de sua formação acadêmica. Este projeto busca despertar o interesse dos alunos em um jogo que de maneira lúdica pode agregar muito na formação e educação continuada de Arquitetura e Urbanismo, podendo ser aproveitado em outras disciplinas e utilizado mesmo fora das aulas em uma perspectiva de autodesenvolvimento como uma ferramenta de entretenimento que converge conhecimento específico da seara da arquitetura e do planejamento urbano, tecnologia e diversão.

O caráter interdisciplinar do referido projeto evidencia interfaces com outras disciplinas da grade do curso de Arquitetura e Urbanismo, a saber, Introdução à Arquitetura e Urbanismo; Conforto, Saúde e Segurança; Teoria e História da Arquitetura, Urbanismo e Paisagismo; Planejamento Territorial, Ambiental e Urbano. Da mesma forma, este projeto possibilita aos alunos explorar uma série de novos conhecimentos relacionados ao planejamento e gestão urbana que vão além do curso de Arquitetura e Urbanismo, como por exemplo, finanças públicas, estatística, cartografia, geoprocessamento, estrutura econômica, setores produtivos, transportes e obras públicas, logística, engenharia, infraestrutura, dentre outros.

Com a utilização do SimCity, os estudantes podem verificar em ambiente virtual simulado a aplicabilidade e efetividade de instrumentos e mecanismos da política urbana e políticas setoriais: zoneamento urbanístico, definição de índices urbanismos, uso e ocupação do espaço urbano, mobilidade, modais de transportes, saneamento, habitação, abastecimento hídrico, matriz energética, entre outros. Além disso, as ferramentas do jogo possibilitam aos alunos estudarem questões ligadas ao emprego, renda, setores econômicos e sua relação espacial com a cidade, segurança pública, saúde, educação e outros temas relacionados às políticas públicas diversificadas. Em síntese, a dinâmica didático-pedagógica elaborada pelo projeto "Cidades Virtuais" propicia aos alunos compreenderem o fenômeno urbano a partir das formas, funções, estruturas e processos relacionados à construção e desenvolvimento das cidades (SANTOS, 1992). 


\section{MATERIAIS E MÉTODOS}

Como identificado, o projeto "Cidades Virtuais" foi concebido no 10 semestre de 2014. Nesse período, toda atenção foi despendida pelo Professor responsável para acoplar de forma adequada e conjugada o referido projeto no plano da disciplina e planejamento das aulas, visando satisfazer os objetivos e otimizar os resultados.

O "Cidades Virtuais" foi implementado no 2올 semestre letivo de 2014 na disciplina de "Fundamentos sociais, econômicos e ambientais" com os alunos do 5o período da graduação de Arquitetura e Urbanismo da Universidade Vila Velha (UVV). Esta disciplina possui carga horária de $60 \mathrm{~h}$. A dinâmica didático-pedagógica do projeto utiliza um sexto da carga horária total da disciplina (10h).

Nesta porção de tempo, os alunos são orientados e supervisionados pelo Professor, bem como praticam os conhecimentos, competências, habilidades e atitudes da disciplina com a utilização das ferramentas do jogo SimCity nas seguintes instâncias:

a) Instrução sobre o histórico, a instalação, as regras e ferramentas do jogo;

b) Estabelecimento constante de pontes entre a vertente teórico-conceitual da disciplina com a dinâmica do jogo;

c) Orientação aos grupos de trabalho;

d) Supervisão e acompanhamento da evolução das cidades virtuais planejadas e gerenciadas pelos estudantes; $\mathrm{e}$

e) Apresentação em formato de seminário, quando as equipes relatam e explicitam em sala de aula os resultados alcançados na gestão das cidades virtuais ao longo do semestre letivo.

A citada turma possuía 26 estudantes e foi dividida em 5 equipes no início do semestre. Para cada equipe foi disponibilizado um jogo que foi instalado em pelo menos um notebook por grupo. Geralmente, os alunos do curso de arquitetura e urbanismo utilizam notebooks para cumprir as atividades das disciplinas do quadro de projeto arquitetural e urbanismo. Aplicativos como o AutoCAD, Sketch Up, Revit, 3D Studio MAX e ArcGIS são constantemente utilizados pelos alunos da UVV tanto em atividades em sala de aula, quanto em atividades extraclasse. Dessa forma, os softwares do jogo SimCity podem ser instalados nos notebooks dos alunos sem maiores problemas. Apenas uma precaução em relação à versão foi tomada. Para evitar problemas de processamento gráfico nos computadores dos alunos, por conta de configurações básicas, a versão do SimCity 4 foi escolhida como a melhor opção para o projeto "Cidades Virtuais". Esta é uma versão mais leve do jogo e não

(C) ETD-Educação Temática Digital Campinas, SP $\quad$ v.19 $\quad$ n.2 $\quad$ p.532-549 abr./jun. 2017 
exige muito do hardware do notebook para o processamento das informações e gráficos do simulador.

Essa versão do SimCity 4 possibilita práticas de planejamento, construção e gerenciamento de uma cidade a partir de um território delimitado. Neste espaço é possível modelar a topografia, hidrografia, cobertura florestal e definir espécies de fauna e flora no início do jogo, ou seja, na etapa denominada "modo Deus". Na etapa seguinte, o estudante assume o "modo Prefeito" e passa a planejar e gerenciar a cidade, controlar o orçamento e finanças municipais, monitorar as condições ambientais e administrar uma série de questões urbanas, como por exemplo, o zoneamento agrário, industrial, residencial e comercial, manutenção de infraestrutura, saneamento básico, vias públicas, educação, saúde, segurança e greves de funcionários públicos. Tal gestão se dá com o apoio de um quadro virtual de Secretários que dão suporte à tomada de decisão com tabelas, gráficos, mapas de hot spot, relatórios estatísticos. Planejar, construir e gerenciar a cidade com os melhores indicadores sociais, econômicos e ambientais empreendendo a qualidade de vida e atendendo os anseios da população significa o sucesso no jogo.

Com a escolha de utilização dos recursos tecnológicos dos quais dispõe o aluno, ou seja, os notebooks, possibilitou-se a liberação de um eventual laboratório de informática que ficaria comprometido durante 30 minutos por semana. Este laboratório pode ser melhor aproveitado, de forma mais eficiente, por uma disciplina que necessite mais do uso de estações desktops. Os alunos podem praticar as competências, habilidades e atitudes proporcionados por este projeto em tempo extraclasse graças à praticidade oferecida pelos notebooks. Além disso, os recursos de datashow e comunicação visual da Instituição possibilitam o suporte necessário para a orientação docente, acompanhamento e apresentação dos resultados alcançados pelas equipes em sala de aula.

A divisão da turma em equipes favorece o debate, trabalho em grupo e aprendizado cooperativo (Figura 1). Dessa forma, o Professor instrui e supervisiona o trabalho de maneira geral com a turma e presta orientação particularizada em cada equipe fomentando o debate e estabelecendo pontes entre os conhecimentos adquiridos na vertente teóricoconceitual da disciplina e na parte prática da simulação computacional de gerenciamento de cidades (Figura 2).

Em cada equipe é eleito um líder que representa a figura do gestor maior da cidade (Figura 3). Os demais membros das equipes assumem importantes papeis de conselheiros, planejadores e secretários municipais. O respeito às diversidades e a sociabilidade são fundamentais, pois o objetivo de todos é o sucesso coletivo da equipe para alcançar os

\section{(C) ETD-Educação Temática Digital Campinas, SP v.19 n.2 p.532-549 abr./jun. 2017}


melhores resultados para a cidade virtual construída e gerenciada por eles. A atividade lúdica do jogo desafia os alunos estimulando o desenvolvimento do raciocínio lógico, reflexivo e analítico que é exercitado individualmente e coletivamente nas equipes.

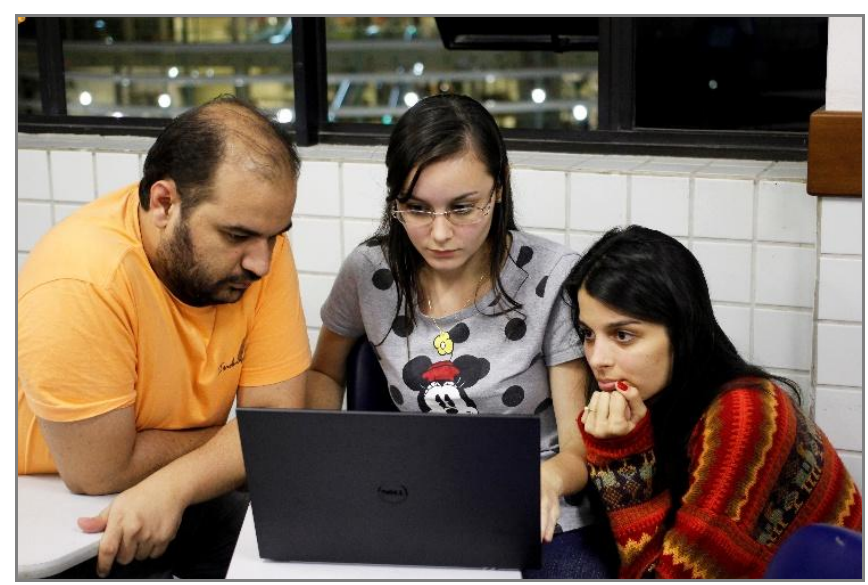

FIGURA 1 - Estudantes do 5o período de Arquitetura e Urbanismo envolvidos com a dinâmica do jogo SimCity 4

Fonte: o autor

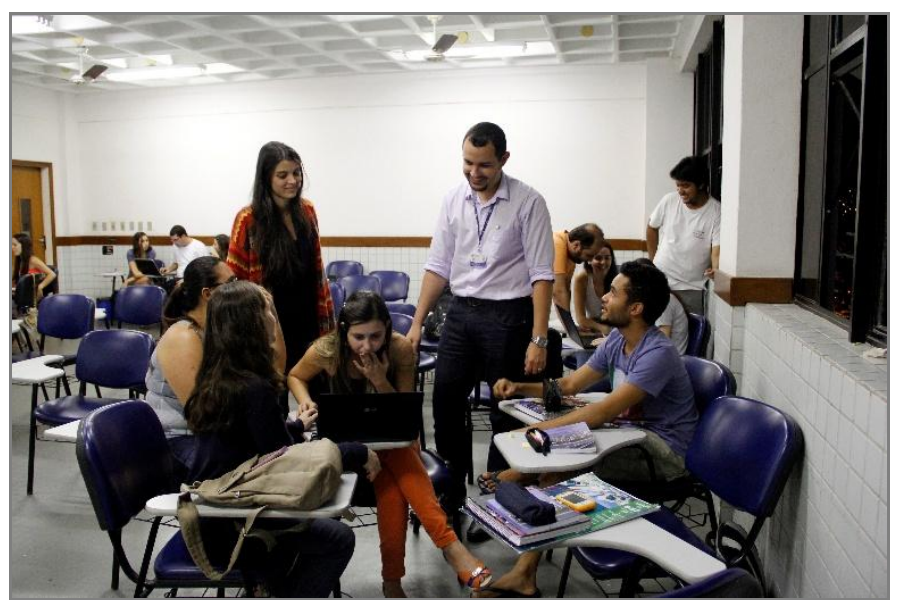

FIGURA 2 - Professor supervisionando e acompanhando a evolução das cidades planejadas e gerenciadas pelos estudantes

Fonte: o autor 


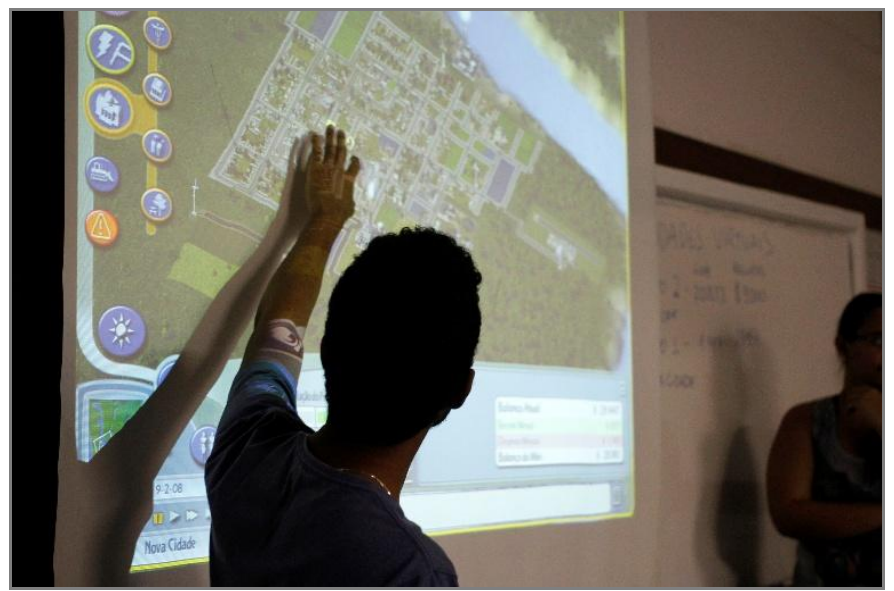

FIGURA 3 - Estudante, líder de uma das equipes, apresentando em seminário os resultados alcançados na gestão da cidade

Fonte: o autor

Como já destacado, um dos fundamentos do projeto reside em possibilitar ao aluno refletir em uma perspectiva heurística para desenvolver e alcançar soluções para os diversos problemas complexos das cidades contemporâneas, como por exemplo, violência, desemprego, déficit habitacional, pobreza e poluição. $O$ trabalho em equipe com foco na solução de problemas como estes, o acompanhamento das evoluções das cidades virtuais e a apresentação dos resultados alcançados estimulam constantemente a capacidade de comunicação interpessoal e a capacidade de argumentação com o Professor, parceiros de equipe e com os colegas da sala de aula.

Para estimular o engajamento das equipes em uma competição positiva são dados pontos de participação nas avaliações bimestrais da disciplina. A pontuação máxima no segundo bimestre é obtida pela equipe que apresenta os melhores indicadores sociais, econômicos e ambientais de sua cidade planejada e gerenciada no ambiente virtual do jogo SimCity ao longo do semestre. De forma individual os alunos são estimulados a submergir na dinâmica didático-pedagógica, pois questões relacionadas ao jogo que explicitem o nexo entre a vertente teórico-conceitual da disciplina podem ser cobradas nas avaliações bimestrais.

\section{ANÁLISE DOS RESULTADOS}

Desde seu primeiro semestre de implantação $(2014 / 2)^{\text {iv }}$, o projeto "Cidades Virtuais" demonstra que alcança os objetivos previstos ao possibilitar de forma efetiva a conexão entre a vertente teórico-conceitual da disciplina de Fundamentos e as experiências práticas proporcionadas pela dinâmica com o jogo SimCity, bem como favoreceu o resgate e aproveitamento do conhecimento cumulativo das demais disciplinas já cursadas pelos

(C) ETD-Educação Temática Digital Campinas, SP v.19 $\quad$ n.2 $\quad$ p. 532-549 abr./jun. 2017 
estudantes, aprimorando assim o processo de ensinoaprendizagem.

Com isso, as competências, habilidades e atitudes dos estudantes do curso de Arquitetura e Urbanismo foram exercitadas de maneira lúdica e instigante. Prova disso foi o interesse dos estudantes nas aulas da disciplina de Fundamentos ao longo do 20 semestre letivo de 2014. Em alguns dias, os alunos permaneciam em sala além do horário programado, pois ficavam entretidos buscando construir a cidade mais perfeita possível e gerenciando os problemas na busca de soluções adequadas para questões urbanas complexas.

O trabalho em equipe além de estimular as competências coletivas de gestão e organização, também proporciona incentivos à criatividade dos estudantes para aplicar os conceitos e teorias da disciplina de fundamentos, de forma dinâmica e inovadora, na construção de cidades virtuais com indicadores sociais, econômicos e ambientais que garantem padrões satisfatórios de cidadania e sustentabilidade. O grande desafio não reside na construção das cidades, mas sim se revela na capacidade e comprometimento de gerenciar o ambiente urbano com todas suas nuanças e complexidades.

De certa forma, os desafios inerentes ao trabalho em equipe e à reflexão sobre o fenômeno urbano exigem, dos estudantes, atitudes que demonstrem maior flexibilidade no raciocínio lógico e reflexivo, postura versátil, abertura de espírito e visão holística. Essas são características essenciais para o sucesso dos estudantes em alcançarem postos de estágio e emprego em prefeituras, secretarias estaduais, empresas de consultoria e até mesmo se prepararem melhor para provas de avaliação, como o Exame Nacional de Desempenho de Estudantes (ENADE), e concursos públicos.

O estimulo em alcançar pontos de participação nas avaliações bimestrais contribui para que os alunos se engajem em uma competição positiva para descobrir qual equipe desenvolverá a cidade com os melhores indicadores. Da mesma forma, o trabalho em ambiente simulado favorece a promoção de uma postura de comprometimento pessoal e profissional nos alunos, uma vez que eles são colocados na posição de gestores, planejadores e tomadores de decisão de questões complexas das cidades que acabam envolvendo a qualidade de vida, expectativas e rotinas das populações que residem nesses espaços urbanos.

Nesse sentido, este projeto está contribuindo para difundir na sociedade acadêmica práticas diferenciais, modernas e inovadoras de ensinoaprendizagem desenvolvidas na UVV. A comprovação de algumas informações apresentadas neste texto pode ser encontrada na

\section{(C) ETD-Educação Temática Digital Campinas, SP $\quad$ v.19 n.2 $\quad$ p. 532-549 abr./jun. 2017}


repercussão de mídia espontânea publicada desde o 2o semestre de 2014 . Dentre as matérias veiculadas listam-se as seguintes, em conjunto com seus respectivos links para acesso:

a) Quadro CBN Universidades da Rádio Central Brasileira de Notícias (CBN): data da publicação 04/12/2014

(http://gazetaonline.globo.com/index.php?id=/cbn vitoria/comentaristas/cbn universidad e/index.php)

b) Homepage da UVV: data da publicação 09/12/2014

(http://www.uvv.br/comunicacao/noticias/Noticia-Detalhe.aspx?7199)

c) Homepage do Observatório das Metrópoles: data da publicação 25/02/2016

(http://observatoriodasmetropoles.net/index.php?option=com k2\&view=item\&id=1483\%3 Acidades-virtuais-uso-de-games-para-estudos-urbanos\&ltemid=164)

d) Homepage da Outra Cidade: data da publicação 29/02/2016

(http://outracidade.com.br/professor-de-arquitetura-usa-simcity-em-sala-de-aula/)

e) Programa Radioatividade da Rádio Jovem Pan de São Paulo: data da publicação 01/03/2016

(http://blog.jovempan.uol.com.br/radioatividade/2016/03/01/professor-usa-jogo-derealidade-virtual-para-ensinar-arquitetura/)

Além destes e outros veículos de comunicação que repercutiram o "Cidades Virtuais", as redes sociais estão contribuindo para difundir e compartilhar as experiências do projeto. Em 25 de fevereiro de 2016 a rede nacional de pesquisa do Instituto Nacional de Ciência e Tecnologia (INCT) Observatório das Metrópoles divulgou na sua fanpage do Facebook uma matéria sobre o projeto "Cidades Virtuais". Nesta publicação foram registradas, em menos de um mês, mais de 300 "curtidas", mais de 260 "compartilhamentos" e centenas de "comentários".

Alguns dos comentários postados na fanpage do INCT Observatório das Metrópoles podem ser conferidos abaixo:

Que legal! Fui muito viciado em SimCity 4.... e não achava que as tantas horas que eu passava jogando eram em vão e tinham sim um aprendizado legal sendo estimulado. Hoje sou geógrafo e trabalho com planejamento territorial...rs (Herlan Alcantra em 25/02/2016).

Aula interessante, e mais dinâmica que acaba dando mais interesse a nós alunos saindo da rotina. Um método bem curioso mais que a proposta bastante positiva (Camila Viana em 29/02/2016).

A iniciativa merece aplausos! Eu gostei bastante da proposta de inserir o jogo nas aulas (Nayra Segal em 29/02/2016).

(C) ETD-Educação Temática Digital Campinas, SP $\quad$ v.19 $\quad$ n.2 $\quad$ p.532-549 abr./jun. 2017 
Muito motivador essa nova alternativa de ensino, porque a partir das aulas teóricas vamos poder colocar de certa forma em prática, em uma cidade virtual. 0 que faz também entendermos melhor como funciona uma cidade e o legal é a interdisciplinaridade das disciplinas, que é onde envolve todos os conhecimentos adquiridos até agora no curso. Super apoio essa dinâmica!!! (Leticia Gobetti em 29/02/2016).

Um estilo inovador de aula, tornando o aprendizado mais descontraído e deixando o urbanismo mais visível e dinâmico para a percepção dos estudantes, com a utilização de um modelo computacional bem feito e adequado para o objetivo proposto!!! (Gabriel Cani de Almeida em 29/02/2016).

Vivemos numa Era Urbana, e todos estão vivendo e produzindo na cidade... E esse jogo é uma forma de nos dar um planejamento territorial, ambiental e urbano, dando uma experiência única de gerenciar uma cidade a partir de ideias e conceitos já criados para ver se realmente funcionam. Uma ideia excelente! (Lídia Drago em 29/02/2016).

Uma maneira interessante de aproximar o aluno/arquiteto do seu campo de trabalho. Visando sempre a análise de vários pontos a serem inseridos no projeto final (Mateus Marcarini Zon em 29/02/2016).

Esta atividade lúdica e inovadora proporcionada pelo projeto "Cidades Virtuais" está colaborando para aprimorar o ensinoaprendizagem na disciplina de Fundamentos do curso de Arquitetura e Urbanismo da UVV. Como um futuro aperfeiçoamento estuda-se a possibilidade de trabalhar concomitantemente este projeto em plataformas de smartphones, considerando que já existe uma versão gratuita do jogo SimCity para essas novíssimas tecnologias.

\section{CONSIDERAÇÕES FINAIS}

O projeto "Cidades Virtuais", que está sendo empreendido desde o segundo semestre de 2014 na Universidade Vila Velha (UVV), está proporcionando aos estudantes de Arquitetura e Urbanismo uma perspectiva alternativa no processo de ensino ensinoaprendizagem. Como visto, o projeto é suportado pela inovação tecnológica caracterizada pelo aprimoramento das aulas via a utilização do simulador de cidades, o SimCity.

Esta ferramenta tecnológica está potencializando o processo de ensinoaprendizagem no curso de Arquitetura e Urbanismo da UVV. O maior interesse e engajamento dos estudantes nas dinâmicas didático-pedagógicas aqui descritas são algumas das transformações proporcionadas pelo projeto "Cidades Virtuais".

A divulgação do citado projeto pelos veículos de comunicação e redes sociais está contribuindo para difundir e compartilhar as experiências percebidas pelo professor e

(C) ETD-Educação Temática Digital Campinas, SP $\quad$ v.19 $\quad$ n.2 $\quad$ p.532-549 abr./jun. 2017 
alunos em sala de aula. Como constatado, as ideias contidas no projeto "Cidades Virtuais" são passíveis de serem aperfeiçoadas, adequadas e aplicadas em vários campos do conhecimento e em diferentes ambientes universitários e/ou de ensino, escolas de ensino médio, por exemplo, no Brasil ou outros países.

O mérito do projeto "Cidades Virtuais" foi reconhecido e contemplado pelo "Prêmio Inovação Acadêmica Dr. Aly da Silva", também conhecido como Prêmio INOVA, promovido pela Universidade Vila Velha. Na edição de 2015, o "Cidades Virtuais" configurou entre os projetos vencedores do prêmio INOVA-UVV. A banca examinadora do prêmio foi composta por uma equipe interdisciplinar, sendo formada pelo Reitor, Pró-Reitor Acadêmico, Diretor do Departamento de Planejamento e Ensino (DPE), Coordenadores Gerais das áreas Humanas, Saúde e Tecnológica da UVV.

Diante disso, este texto soma a contribuição e experiências do projeto "Cidades Virtuais", acumulados até este momento, à produção do conhecimento sobre práticas inovadoras de ensinoaprendizagem universitário e espera que futuros desdobramentos possam surgir e proporcionar avanços nas Instituições de Ensino Superior (IES), bem como em outros níveis de ensino.

\section{REFERÊNCIAS}

ABEA, Associação Brasileira de Ensino de Arquitetura e Urbanismo. Cadernos ABEA. Disponível em: www.abea-arq.org.br. Acesso em: 03 fev. 2016.

BENÉVOLO, Leonardo. História da arquitetura moderna. São Paulo, SP: Perspectiva. 1989.

CARLOS, Ana Fani Alessandri. A cidade. 7. ed. São Paulo, SP: Contexto, 2003.

CASTELLS, Manuel. A questão urbana. Rio de Janeiro, RJ: Paz e Terra, 1983.

CAVALCANTI, Clóvis. Desenvolvimento e natureza: estudos para uma sociedade sustentável. São Paulo, SP: Cortez, 1995.

CORRÊA, Roberto. O espaço urbano. São Paulo, SP: Ática, 1989.

FERNANDES, Edésio. Do código civil ao estatuto da cidade: algumas notas sobre a trajetória do direito urbanístico no Brasil. In: VALENÇA, Márcio. Cidade (I) Legal. Rio de Janeiro, RJ: Mauad X, 2008, pp. 43-62.

FERRARI, Célson. Curso de planejamento municipal integrado. São Paulo, SP: Pioneira, 1982.

\section{(C) ETD-Educação Temática Digital Campinas, SP $\quad$ v.19 n.2 $\quad$ p. 532-549 abr./jun. 2017}


GENTILLI, Pablo. Pedagogia da exclusão? Crítica ao neoliberalismo em educação. Petrópolis, RJ: Vozes, 2001.

HARVEY, David. A justiça social e a cidade. São Paulo, SP: Hucitec, 1980.

HARVEY, David. Condição pós-moderna. 16. ed. São Paulo, SP: Loyola, 2007.

IBGE, Instituto Brasileiro de Geografia E Estatística. Regiões de Influência das Cidades REGIC 2007. Rio de Janeiro, RJ: IBGE, 2008.

IBGE, Instituto Brasileiro de Geografia E Estatística. Series estatísticas. Disponível em: www.ibge.gov.br. Acesso em: 03 fev. 2016.

JOLY, Fernando. A cartografia. Campinas, SP: Papirus, 1990.

LEFEBVRE, Henri. A revolução urbana. Belo Horizonte, MG: UFMG, 1999.

LEFEBVRE, Henri. O direito à cidade. São Paulo, SP: Documentos, 1969.

LYNCH, Kevin. A boa forma da cidade. Lisboa: Edições 70, 1999.

LYNCH, Kevin. A imagem da cidade. São Paulo, SP: Martins Fontes, 1980.

MASSEY, Doreen. Pelo espaço: uma nova política da espacialidade. Rio de Janeiro, RJ: Bertrand Brasil, 2008.

MENDES, Rosana. GRANDO, Regina. O jogo computacional SimCity 4 e suas potencialidades pedagógicas para as aulas de matemática. In: Zetetiké: Revista de educação matemática. CEMPEM - FE - UNICAMP, v. 16, n. 29, jan./jun, 2008.

MONTEIRO, Ana Maria Reis de Goes. A construção de um novo olhar sobre o ensino de arquitetura e urbanismo no Brasil: os 40 anos da Associação Brasileira de Ensino de Arquitetura e Urbanismo. Brasília: ABEA, 2013.

MOURA, Manoel. A construção do signo numérico em situação de ensino. Tese (doutorado). São Paulo, SP: Faculdade de Educação, Universidade de São Paulo (USP), 1992.

NASCIMENTO, José. ALBUQUERQUE, Glauce. Caminhos (re) buscados e (re) criados em uma cidade barroca: uma experiência de atividade integrada em componentes curriculares do curso de Arquitetura e Urbanismo da UFRN. In: Anais do XXXIV Encontro Nacional sobre ensino de arquitetura e urbanismo - ENSEA e XVIII congresso nacional da associação brasileira de ensino de arquitetura e urbanismo - CONABEA. pp. 308-320. Natal, RN: ABEA, 2015.

OCDE, Organização para Cooperação e Desenvolvimento Econômico. Manual de Oslo: diretrizes para coleta e interpretação de dados sobre inovação. 3. ed. Brasília, DF: ARTI/FINEP, 2005.

(c) ETD-Educação Temática Digital Campinas, SP v.19 $\quad$ n.2 $\quad$ p. 532-549 abr./jun. 2017 
ONU, Organização das Nações Unidas. Department of Economic and Social Affairs - ESA. Disponível em: www.esa.un.org. Acesso em: 04 fev. 2016.

ONU, Organização das Nações Unidas. World urbanization prospects: the 2014 revision. Nova lorque: 2015. Disponível em: www.esa.un.org. Acesso em: 04 fev. 2016.

RIBEIRO, Luiz Cesar. A ordem urbana na metrópole do Rio de Janeiro: caminhos e síntese. In: RIBEIRO, Luiz Cesar. Rio de Janeiro: transformações na ordem urbana: território, coesão social e governança democrática. Observatório das Metrópoles. Rio de Janeiro, RJ: Letra Capital, 2015.

RIBEIRO, Luiz Cesar. Transformações da ordem urbana na metrópole liberal-periférica: 1980/2010. Hipóteses e estratégia teórico-metodológica para estudo comparativo. Rio de Janeiro, RJ: Observatório das Metrópoles, 2013.

SANTOS, Milton. A natureza do espaço: técnica e tempo, razão e emoção. 4. ed. São Paulo, SP: Edusp, 2006.

SANTOS, Milton. A urbanização brasileira. 5. ed. São Paulo, SP: Edusp, 2005.

SANTOS, Milton. Espaço e método. 3. ed. São Paulo, SP: Nobel, 1992.

SANTOS, Milton. O espaço dividido: os dois circuitos da economia urbana dos países subdesenvolvidos. 2. ed. São Paulo, SP: Edusp, 2004.

\footnotetext{
' Revisão gramatical do texto sob a responsabilidade da equipe da revista ETD

ii Manual editado pela Organização para Cooperação e Desenvolvimento Econômico - OCDE que estabelece as diretrizes para coleta e interpretação de dados sobre inovação. No Brasil, a agência Financiadora de Estudos e Projetos - FINEP do Ministério da Ciência e Tecnologia ficou responsável pela tradução da mencionada referência.

iii Jogo computacional produzido pela empresa norte-americana Eletronic Arts (EA).

iv O projeto foi implementando novamente com êxito nos semestres 2015/1 e 2015/2. O mesmo está programado para ser aplicado nos próximos semestre nas turmas do 50 período da graduação de Arquitetura e Urbanismo da UVV e, provavelmente, em disciplinas de outros cursos da Instituição, como por exemplo, Fundamentos do Ensino de Geografia na graduação de Pedagogia.
} 